\title{
ОПРЕДЕЛЕНИЕ ПАРАМЕТРОВ ДАЛЕКИХ ЗЕМЛЕТРЯСЕНИЙ ПО ДАННЫМ КАРЕЛЬСКОЙ СЕЙСМИЧЕСКОЙ СЕТИ
}

\author{
И. А. Зуева \\ Институт Геологии КарНЦ РАН, г. Петрозаводск
}

Поступила в редакцию 30 октября 2017 г.

\begin{abstract}
Аннотация: были определены параметры далекого землетрясения по записям Карельской сейсмической сети. Построен спектр сигналов продольных волн. Использован метод определения гипоцентров далеких землетрясений, предложенный автором книги [1]. Координать гипоцентра принято искать путем минимизации функиионала суммы квадратов невязок, между расчетными и наблюдаемыми временами прихода упругих волн к точке приема. Примененный в работе метод определения координат гипочентра заключается в минимизаџии функиионала в пространственных переменных, что позволяет повысить устойчивость определения координат гипоцентра землетрясения. Создан алгоритм, по которому написана программа HуроGlobal. Получень координаты гипоцентра события.
\end{abstract}

Ключевые слова: сейсмическая сеть, станция, землетрясение, сейсмограмма, волновые формы, спектр, эпищентр, гипоцентр.

\section{DETERMINATION OF LONG-TERM EARTHQUAKES BY DATA OF THE KARELIAN SEISMIC NETWORK}

\begin{abstract}
: in this paper, the parameters of a distant earthquake were determined from records of the Karelian seismic network. A spectrum of signals of longitudinal waves is constructed. The method of determining the hypocenters of remote earthquakes, proposed by the author of the book [1], was used. The coordinates of the hypocenter are usually searched for by minimizing the functional of the sum of the squares of the residuals, between the calculated and observed times of arrival of elastic waves to the receiving point. The method used to determine the coordinates of the hypocenter is to minimize the functional in the spatial variables, which makes it possible to increase the stability of the determination of the coordinates of the hypocentre of the earthquake. An algorithm has been created, according to which the HypoGlobal program is written. The coordinates of the hypocentre of the event are obtained.
\end{abstract}

Keywords: seismic network, station, earthquake, seismogram, waveforms, spectrum, epicenter, hypocentre.

\section{Введение}

На территории Карелии установлена сеть из пяти сейсмических станций $[2,3]$. Она регистрирует события на разных эпицентральных расстояниях. Для слабоактивной в сейсмическом отношении Карелии наиболее яркими сейсмическими событиями являются промышленные взрывы. При анализе волновых форм трудно определить вид события. Часто записи взрывов и землетрясений практически неотличимы, поэтому задача их распознавания очень важна. Результаты исследований необходимы при обработке сейсмических записей на территории Карелии, составлении каталогов. Цель данной работы состояла в разработке методики получения основной информации о далеких землетрясениях, зарегистрированных станциями Карельской сейсмической сети.
Существует множество подходов к распознаванию техногенных событий и землетрясений [4-6]. В данной работе представлен способ определения параметров далеких землетрясений, зарегистрированных станциями Карельской сейсмической сети. Для примера было использовано сейсмическое событие, зарегистрированное станциями KOS6, PITK, PTRZ 23 апреля 2017 года в 06:37:06 по Гринвичу. По спектрам сейсмических сигналов был определен вид события. Далее, были рассчитаны координаты гипоцентра землетрясения.

Для определения координат гипоцентра далеких землетрясений был использован метод, предложенный автором книги [1]. На основе этого метода в данной работе представлен алгоритм его реализации, по которому написана программа HypoGlobal, показаны результаты. 
Сейсмическое событие 23.04.2017.

Спектральный анализ сигнала продольных волн Для распознавания события 23.04.2017 в районе 6 часов 38 минут по Гринвичу на записях Карельской сети был использован спектральный анализ сигнала продольных волн. На (рис. 1) приведены фрагменты волновых форм и амплитудные спектры события. Спектры записей имеют схожую форму. Как видно (рис. 1б) на спектрах наблюдается максимум амплитуд на частотах 0,1-0,4 Гц. Низкочастотный спектр сигнала указывает на естественную сейсмичность события.

Для определения координат гипоцентра данного события была использована программа HypoGlobal, написанная на основе метода [1].

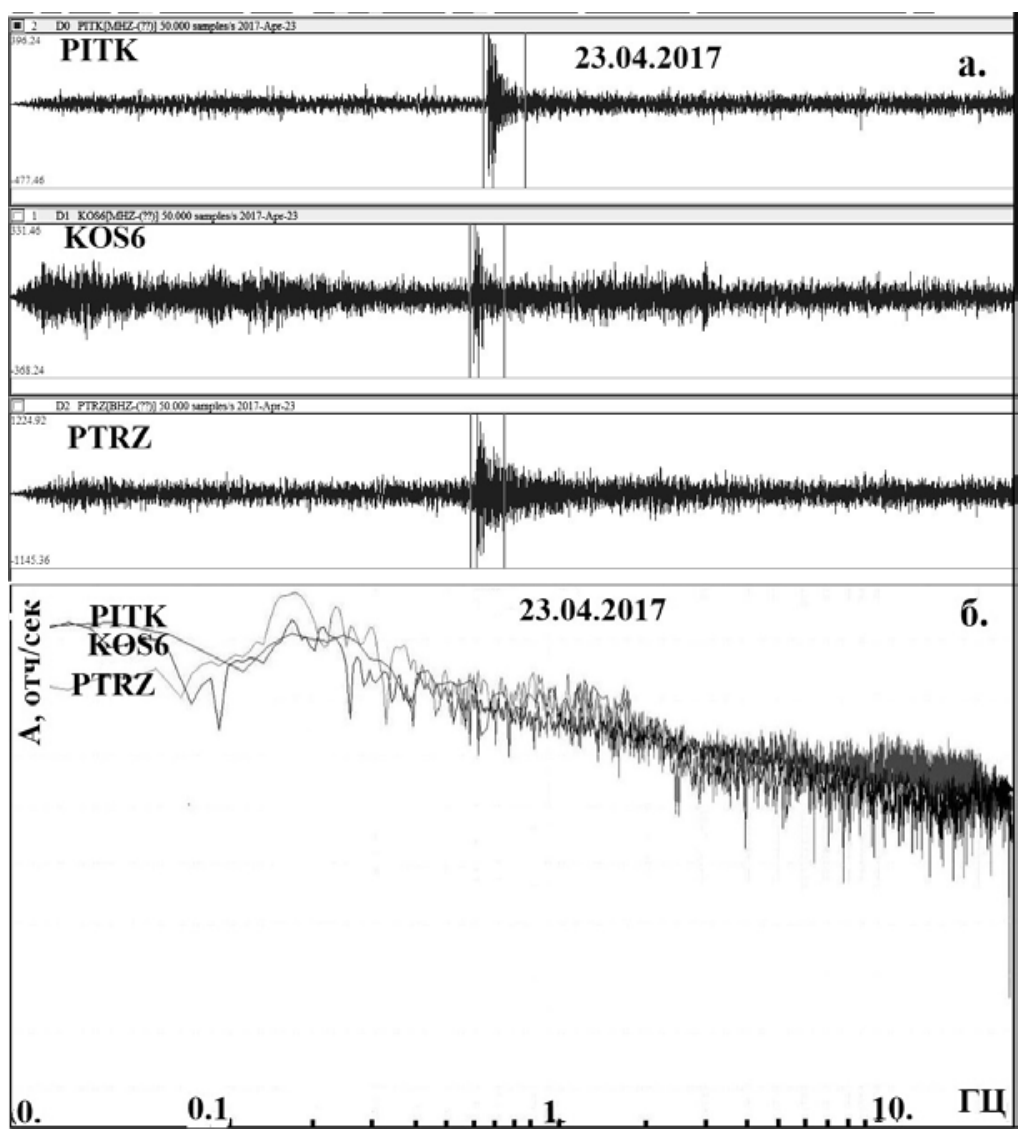

Puc. 1. Сейсмическое событие, зарегистрированное станциями Карельской сети (PITK,KOS6,PTRZ) 23.04.2017: $a$ - вступления продольных волн; $\sigma$ - амплитудные спектры сигналов.

\section{Основы метода}

Практически все современные методы определения координат гипоцентров сводятся к минимизации функционала невязок теоретических $\mathrm{t}_{\mathrm{i}}$ и наблюденных

$t_{i}$ времен пробега сейсмических волн.

$$
S_{t}=\sum_{i=1}^{n}\left(t_{i}-\tilde{t}_{i}\right)^{2}
$$

Как показано в [1], такой подход к определению координат гипоцентров не является оптимальным.

В [1] для функционала $\mathrm{S}_{\mathrm{t}}$ получена следующая оценка:

$$
S_{t}=\sum_{i=1}^{n}\left(t_{i}-\tilde{t}_{i}\right)^{2} \leq \sum_{i=1}^{n} \rho_{i}\left(D_{i}-d_{i}\right)^{2}+Y(H-h)^{2}=S
$$

где $D_{i}, H$ и $d_{i,} h$ - эпицентральные расстояния и глубины, соответствующие теоретическим и наблю- денным временам пробега сейсмических волн; $\rho_{i}=v_{i}^{-2}$ и $Y=\sum_{i=1}^{n} \rho_{i}-$ весовые множители, характеризующие неоднородность среды.

Из полученного соотношения следует, что малость значения функционала $S_{t}$ не гарантирует малости значений функционалов невязок в определении глубины гипоцентра землетрясения и эпицентральных расстояний, но малость значения функционала $S$ влечет за собой малость значения функционала невязки времен.

Исходя из сказанного, определение координат гипоцентров удаленных землетрясений ставится не как задача минимизации функционала $S_{t}$, как задача минимизации функционала:

$$
S=\sum_{i=1}^{n} \Omega_{i}\left(D_{i}-d_{i}\right)^{2}+(H-h)^{2}+\eta\left(T_{0}-\tau_{0}\right)^{2}
$$


$\eta \quad=1 / W . \quad \sum_{i=1}^{n} \Omega_{i}, W \quad-\quad$ весовые множители, характеризующие неоднородность среды. $D_{i}, H, T_{0}$ определяются из решения системы линейных уравнений [1],[7]:

$$
\left(X_{0} x_{i}+Y_{0} y_{i}+Z_{0} z_{i}\right) / R_{0} R_{i}-T_{0} \tau_{i} v_{i}^{2} / R_{0} R_{i}=\cos \left(d_{i} / R_{i}\right)-\tau_{0} \tau_{i} v_{i}^{2} /\left(R_{0} R_{i}\right) .
$$

где $X_{0}, Y_{0}, Z_{0} \tau_{0} \quad-$ координаты гипоцентра в декартовой системе координат и время возникновения землетрясения (время в очаге); $x_{i}, y_{i}, z_{i}, \tau_{i}-$ координаты регистрирующих станций, зарегистрировавших землетрясение, и времена прихода сейсмических волн на эти

станции $(\mathrm{i}=1, \mathrm{n}) ; v_{i}-$ эффективные скорости распространения сейсмических волн, численно равные отношению расстояния по прямой от і-й станции до гипоцентра к времени пробега сейсмической волны по лучу. Величину $R_{0}=R_{3}-h$, определяем через глубину гипоцентра $h$, отсчитываемую от поверхности Земли, и величину радиуса Земли $R_{3}$. $R_{i}$ - радиус вектор і-ой сейсмической станции [1].

\section{Алгоритм}

На множествах возможных глубин $\mu$ и моментов возникновения землетрясений $\square \vartheta^{\prime}$ ищем значения $h \in$ $\mu$ и $\tau_{0} \in \vartheta^{\prime}$, обеспечивающие минимум функционала $S$ (3) при условии, что величины $X_{0}, Y_{0}, Z_{0}$ и $T_{0}$ определяются из решения системы линейных алгебраических уравнений (4). Задачу решаем перебором, выбирая значения $h$ и $\tau_{0}$ из области определения. Результатами считаются значения, соответствующие минимуму функционала $S$. Схема алгоритма представлена на (рис. 2).

Алгоритм включает следующие этапы:

1. Вычисляем времена пробега сейсмических волн для станции по известным (наблюденным) временам прихода $\tau_{i}$ на станции и выбранному времени в очаге $\tau_{0}:$

$$
t_{i}=\tau_{i}-\tau_{0},
$$

2. Находим значения угловых эпицентральных расстояний $\psi_{i}=d_{i} / R_{i}$ по уравнению годографа рефрагированной волны для сферической Земли, заданному в параметрическом виде, и зависящему от выбранного значения $h$, эффективных скоростей распространения сейсмических волн, лучевого параметра $\alpha$, равного обратному значению скорости сейсмической волны в точке максимального проникновения луча $[1,8,9]$.

$$
\begin{aligned}
& \psi_{i}=\alpha_{i}\left[\int_{R_{3}-h}^{R_{3}}+k \int_{R_{\alpha}}^{R_{3}-h}\right] \frac{1}{\sqrt{[r / v(r)]^{2}-\alpha_{i}^{2}}} \frac{d r}{r}, \\
& t_{i}=\left[\int_{R_{3}-h}^{R_{3}}+k \int_{R_{\alpha}}^{R_{3}-h}\right] \frac{[r / v(r)]^{2}}{\sqrt{[r / v(r)]^{2}-\alpha_{i}^{2}}} \frac{d r}{r}
\end{aligned}
$$

Формулы (5) определяются из функционала Ферма, с применением уравнения Эйлера и функции Гамильтона. $k=0$ для лучей, выходящих вверх из гипоцентра; $k=2$ - для лучей, выходящих вниз из источника; $R_{\square}$-расстояние от центра Земли до точки максимального $\alpha$ проникновения луча. Лучевой параметр $\alpha$ находим по временам пробега $t_{i}[1]$.

3. Вычисленные значения угловых эпицентральных расстояний $\psi_{\mathrm{i}}$, выбранные значения времени в очаге $\tau_{0}$ и глубины $h$ подставляем в правые части системы линейных алгебраических уравнений (СЛАУ) (4) [10, 11].

4. Решая систему (4), определяем координаты гипоцентра $X_{0}, Y_{0}, Z_{0}$ и время в очаге $T_{0}$, позволяющие найти эпицентральные расстояния $D_{i}$ и глубины $H$.

5. По наблюденным и теоретическим значениям эпицентральных расстояний, глубин и времени в очаге согласно формуле (3) рассчитываем функционал $S$.

6. Ищем минимальное значение $S$. Если текущее $S$ меньше минимального $S$, то минимальному значению $S$ присваиваем текущее значение.

7. Широта, долгота, глубина гипоцентра и время в очаге, соответствующие минимальному значению функционала выводятся как решение задачи.

\section{Исходные данные, результаты}

Для нахождения координат гипоцентра сейсмического события 23 апреля 2017 года были использованы координаты и времена прихода продольных Р-волн с мировых сейсмических станций, данные Карельской сети, скоростная модель Земли, построенная по геолого-геофизическим данным [12]. Для времени в очаге использовались известные данные [13].

По результатам программы HypoGlobal глубина гипоцентра равна 34 км. Это событие представляет собой естественное сейсмическое событие, вызванное тектоническими процессами. Широта и долгота по результатам программы и данным Единой Геофизической службы РАН (табл. 1) указывают на то, что землетрясение произошло на Сахалине. По данным ЕГС РАН магнитуда равна 5, 3 [13].

Причиной расхождения глубины гипоцентра может быть разное количество выбранных сейсмостанций. В расчете были задействованы 17 станций, тогда как Единой Геофизической службой использовались данные 46 станций. 


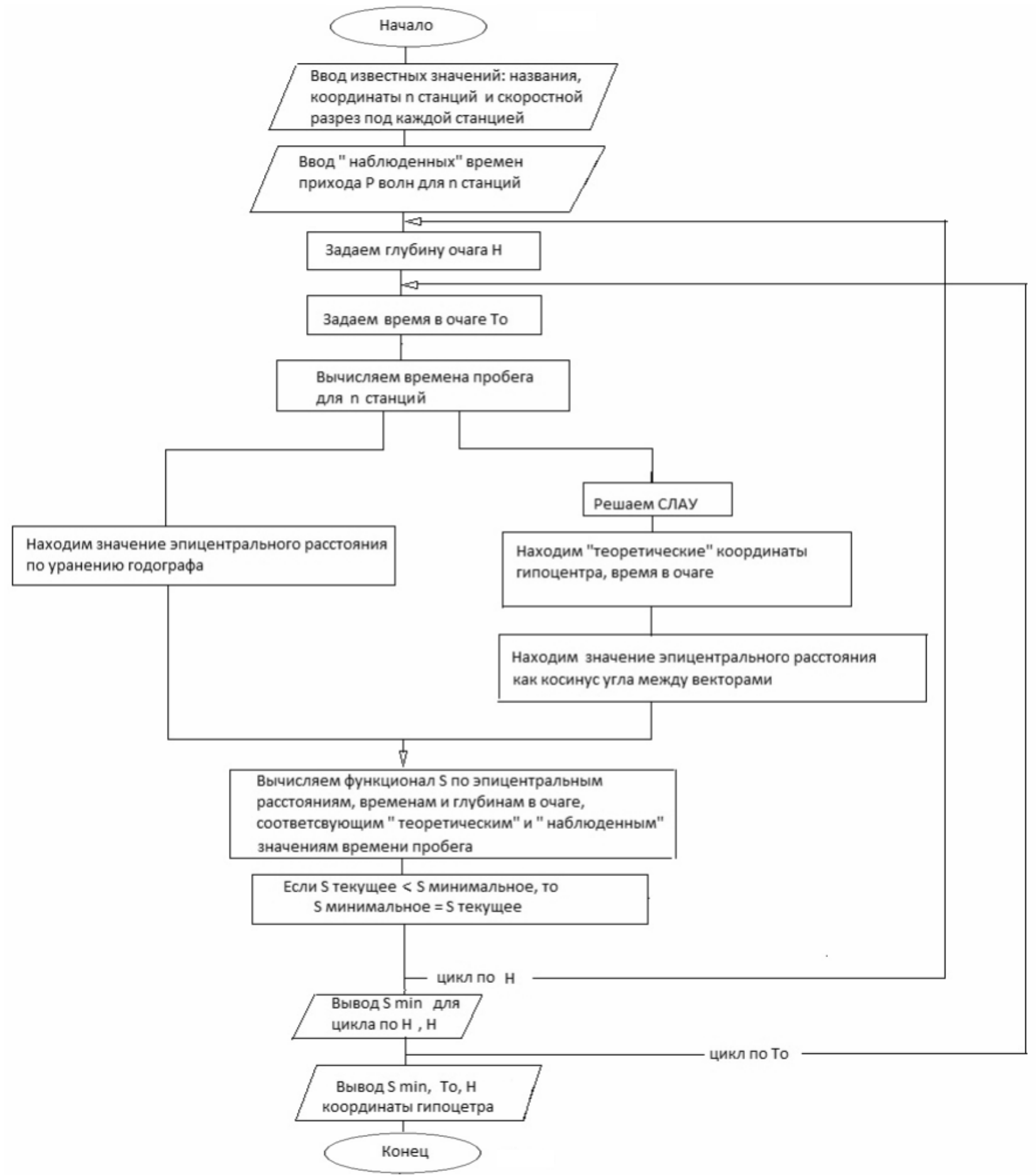

Puc. 2. Блок-схема алгоритма локализации землетрясения.

Таблица 1

Результаты расчета координат гипоиентра по программе HуроGlobal и данным Единой Геофизической службы РАН

\begin{tabular}{|l|c|c|c|}
\hline \multirow{2}{*}{} & \multicolumn{3}{|c|}{ Координаты гипоцентра } \\
\cline { 2 - 4 } & $\begin{array}{c}\text { Широта, } \\
\text { град. }\end{array}$ & $\begin{array}{c}\text { Долгота, } \\
\text { град. }\end{array}$ & $\begin{array}{c}\text { Глубина } \\
\text { гипоцентра, км }\end{array}$ \\
\hline HypoGlobal & 46,057 & 142,5534 & 34 \\
\hline ЕГС РАН & 46,07 & 142,08 & 10 \\
\hline
\end{tabular}

\section{Заключение}

Определение вида и параметров события с участием станций Карельской сейсмологической сети состояло из двух этапов: построения спектров сейсмических сигналов продольных волн, вычисления координат гипоцентра. По результатам проделанной работы было установлено, что событие, зарегистрированное станциями Карельской сети 23.04.2017, произошло на Сахалине.

На основе метода определения гипоцентров далеких землетрясений, предложенного автором книги [1], 
был разработан алгоритм решения задачи. В известных методах определения координат землетрясений минимизируется среднеквадратическая невязка времен пробега сейсмических волн. В работе [1] показано, что минимум функционала невязки времен не гарантирует минимума расстояния между теоретическим и реальным положением гипоцентра. Для определения наилучшего положения гипоцентра в расчетах используется принцип минимизации функционала невязки в пространственных переменных $S$. Основу алгоритма составляют уравнения, связывающие координаты гипоцентра землетрясения с координатами сейсмических станций, и метод перебора возможных значений глубин гипоцентров и времени в очаге.

C помощью программы HypoGlobal были рассчитаны координаты гипоцентра землетрясения на Сахалине 23.04.2017 г. Широта и долгота гипоцентра, полученные Геофизической службой и с помощью HypoGlobal, отличаются друг от друга незначительно. Глубина гипоцентра по программе HypoGlobal paвна 34 км. Данные ЕГС РАН выдают значение 10 км. Вполне возможно, что очаг находится на глубине 34 км, так как метод невязки времен не дает точного значения глубины гипоцентра, как показано в работе [1].

Выражаю благодарность д.ф.-м.н. В. Ю. Бурмину и д.т.н. Белашеву Б. З. за помощь в работе.

Исследование проведено в рамках Госздания ИГ КарНЦ РАН.

\section{ЛИТЕРАТУРА}

1. Бурмин, В.Ю. Оптимизация сейсмических сетей и определение координат землетрясений / В. Ю.Бурмин. - М.: ОИФЗ РАН,1995. - $184 \mathrm{c}$.

2. Зуева, И. А. Характерные черты сейсмических записей промышленных взрывов на Костомукшском железорудном месторождении по данным станций Карельской сети / И. А.Зуева, А. А. Лебедев // Вестн. Воронеж. гос. ун-та. Сер. : Геология. - 2017. - № 2. - С. 133-141.

3. Шаров, Н. В. Землетрясения и микросейсмичность в задачах современной геодинамики Восточно-Европейской платформы / Н. В. Шаров, А. А. Маловичко, Ю. К. Щукин Петрозаводск: Карельский научный центр РАН, Кн. 1: Землетрясения, 2007. - 381 с.

4. Адушкин, В. В. Взрывы и землетрясения на территории Европейской части России / В. В. Адушкин, А. А. Маловичко. - М.: ГЕОС, 2013. -384 с.

5. Годзиковская, А. А. Ретроспективный анализ первичных материалов о сейсмических событиях, зарегистрированных на Кольском полуострове и прилегающих территориях в XX веке / А. А. Годзиковская , В. Э. Асминг, Ю. А. Виноградов - М.: Ваш полиграфический партнер, 2010. -130 с.

6. Морозов, A. Н. О природе сейсмического события, зарегистрированного в Архангельской области 28 марта 2013 года. / А. Н. Морозов, Е. В. Иванова, В. Э. Асминг. // Современные методы обработки и интерпретации сейсмологических данных. Материалы Восьмой Международной сейсмологической школы-- Обнинск: ГС РАН, 2013. - С. 214-218.

7.Закатов, П.С. Курс высшей геодезии / П.С.Закатов. - М.: Недра, 1964.- 504 с.

8. Аки, $K$. Количественная сейсмология: Теория и методы. Т.2. / К. Аки, П. Ричардс. М.: Мир, 1983. - 360 с.

9. Иглин, С. П. Математические расчеты на базе MATLAB / С. П. Иглин.- Спб.: БВХ-Петербург, 2005. - 640 с.

10. Ильин, В. А. Линейная алгебра / В. А. Ильин, Э. Г. Поздняк. - М.: Наука, 1974. - 296 с.

11.Фадеев, Д. К. Вычислительные методы линейной алгебры / Д. К. Фадеев, В. Н. Фадеева. - М.: Физматгиз, 1963. - $734 \mathrm{c}$

12. Бурмин, В. Ю. Скорость распространения продольных сейсмических волн в мантии Земли / В. Ю. Бурмин //Физика Земли. - 2004. - №8.- С. 34-40.

13. Служба Срочных Донесений. - Режим доступа: http://www.ceme.gsras.ru/cgi-bin/new/ccd_quake.pl?dat=201704-23\&l=0 (дата обращения: 15.08.2017)

Institute of Geology of the Karelian Research Centre of the Russian Academy of Sciences

Zueva I. A., senior laboratory researcher

E-mail:ek92wa@mail.ru

Tel.: +7(921)620-37-50 